\title{
Electrodynamics of ionospheric weather over low latitudes
}

Mangalathayil Ali Abdu $u^{1,2^{*}}$

\begin{abstract}
The dynamic state of the ionosphere at low latitudes is largely controlled by electric fields originating from dynamo actions by atmospheric waves propagating from below and the solar wind-magnetosphere interaction from above. These electric fields cause structuring of the ionosphere in wide ranging spatial and temporal scales that impact on space-based communication and navigation systems constituting an important segment of our technology-based day-to-day lives. The largest of the ionosphere structures, the equatorial ionization anomaly, with global maximum of plasma densities can cause propagation delays on the GNSS signals. The sunset electrodynamics is responsible for the generation of plasma bubble wide spectrum irregularities that can cause scintillation or even disruptions of satellite communication/navigation signals. Driven basically by upward propagating tides, these electric fields can suffer significant modulations from perturbation winds due to gravity waves, planetary/Kelvin waves, and non-migrating tides, as recent observational and modeling results have demonstrated. The changing state of the plasma distribution arising from these highly variable electric fields constitutes an important component of the ionospheric weather disturbances. Another, often dominating, component arises from solar disturbances when coronal mass ejection (CME) interaction with the earth's magnetosphere results in energy transport to low latitudes in the form of storm time prompt penetration electric fields and thermospheric disturbance winds. As a result, drastic modifications can occur in the form of layer restructuring (Es-, F3 layers etc.), large total electron content (TEC) enhancements, equatorial ionization anomaly (EIA) latitudinal expansion/contraction, anomalous polarization electric fields/vertical drifts, enhanced growth/suppression of plasma structuring, etc. A brief review of our current understanding of the ionospheric weather variations and the electrodynamic processes underlying them and some outstanding questions will be presented in this paper.
\end{abstract}

\section{Introduction}

Ionosphere is an important domain of the earth's space environment and has been the subject of intensive studies since its discovery in the early years of the 20th century. Because of its ability to modify the properties of radio waves propagating through it, the ionosphere has provided us the means, as well as constraints, for the sustaining radio-based communication and navigations systems. In fact, the ionosphere exercises significant impact on a variety of space-based application systems of our technology-based modern life. Therefore there is growing interest by the scientific community to understand

\footnotetext{
*Correspondence: ma.abdu@inpe.br

${ }^{1}$ Instituto Tecnológico de Aeronáutico (ITA), DCTA,

São Jose dos Campos, Brazil

Full list of author information is available at the end of the article
}

the variability of the ionosphere in terms of its causes and consequences to be able to develop prediction models on the ionospheric weather. Such a goal remains to be a highly challenging task because of the major drivers of the variability arising from sources both below and above the ionosphere. Lower atmospheric regions are the sources of upward propagating waves in the form of tidal modes, gravity waves, and planetary/Kelvin waves that impose significant modifications on the ionospheric dynamics. The forcing from the higher up involves solar ionizing radiation, and solar mass ejections in the form of Earth bound CMEs that cause space weather disturbances when enhanced magnetosphere-ionosphere coupling processes lead to severe modifications of the ionospheric electrodynamics and structuring. 
The ionosphere over low latitudes (in the latitude range $\pm 30^{\circ}$ ) possesses features that are distinct from those of other latitudes, because of the low inclination geomagnetic field lines and the relatively larger fraction of the incident solar ionizing radiation that characterize this region. Over mid-latitudes, the high inclination magnetic field lines make the ambi-polar diffusion of plasma (together with meridional winds) the dominant means of vertical transport required for the layer formation and structuring. In contrast to this, over low latitudes where the magnetic field lines are of low inclination (quasi horizontal), the vertical transport of plasma is governed by zonal electric fields generated by ionospheric dynamo or by penetration electric field originating from magnetospheric dynamo. A schematic diagram depicting the sources of the electric fields and how they drive the major phenomenology constituting the low latitude ionospheric weather elements is presented in Fig. 1. The upward propagating winds and waves, associated with tidal oscillation modes, gravity waves and planetary/Kelvin waves, interact with the magnetized conducting ionosphere of the dynamo region generating the electric fields. The zonal component of the electric field produces vertical $E \times B$ plasma drift whose well-known manifestation is the equatorial plasma fountain that produces the equatorial ionization anomaly (EIA) characterized by two low latitude ionization crests of global maximum of plasma densities, first discovered in 1938 by Namba and Maida

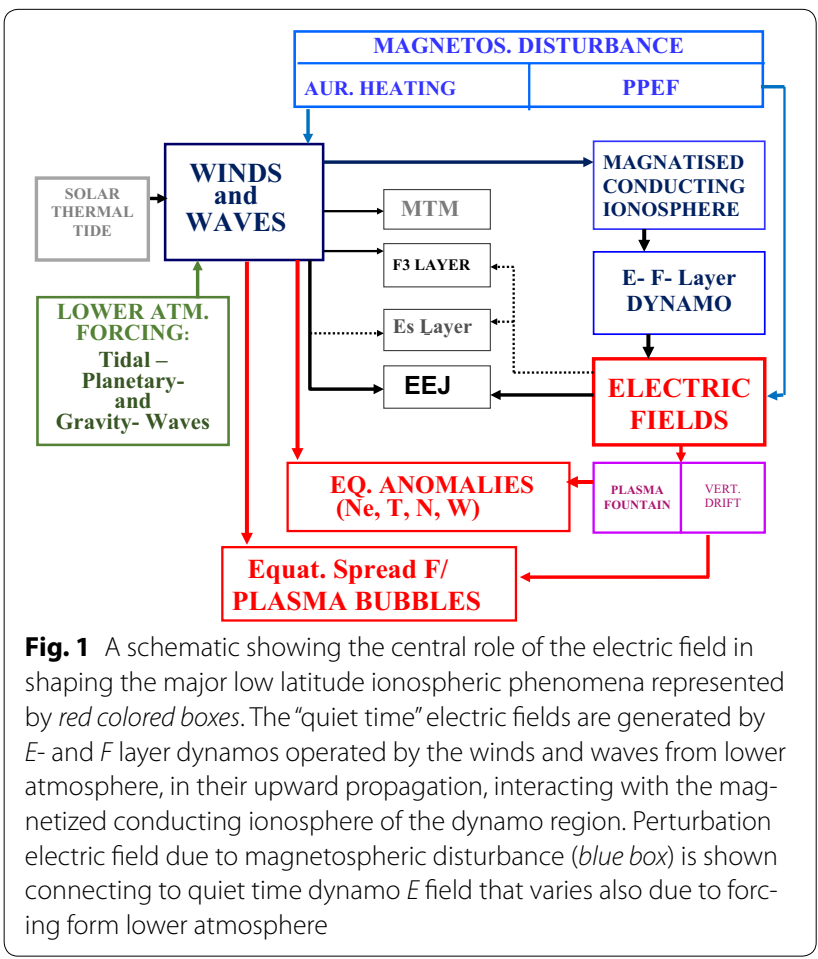

(1938). The large plasma density of the EIA crests causes increased group delay of the GNSS signals leading to errors in positioning and navigation applications.

The quiet time vertical plasma drift (zonal electric field), measured by ROCSAT-1 satellite (at $600 \mathrm{~km}$ ) is presented in Fig. 2 in terms of their seasonal mean values as a function of local time and longitude, for the equinoctial and solstice seasons (Fejer 2011). The daytime upward plasma drift due to the $E$ layer dynamo is responsible for the development of the EIA that attains maximum intensity in the afternoon hours. An evening enhancement in the vertical drift (before its reversal to downward), known as the prereversal enhancement in the vertical drift (PRE), clearly observable around 18-19 LT during equinox and summer solstice at many longitudes (Fig. 2), is responsible for a post-sunset resurgence of the EIA.

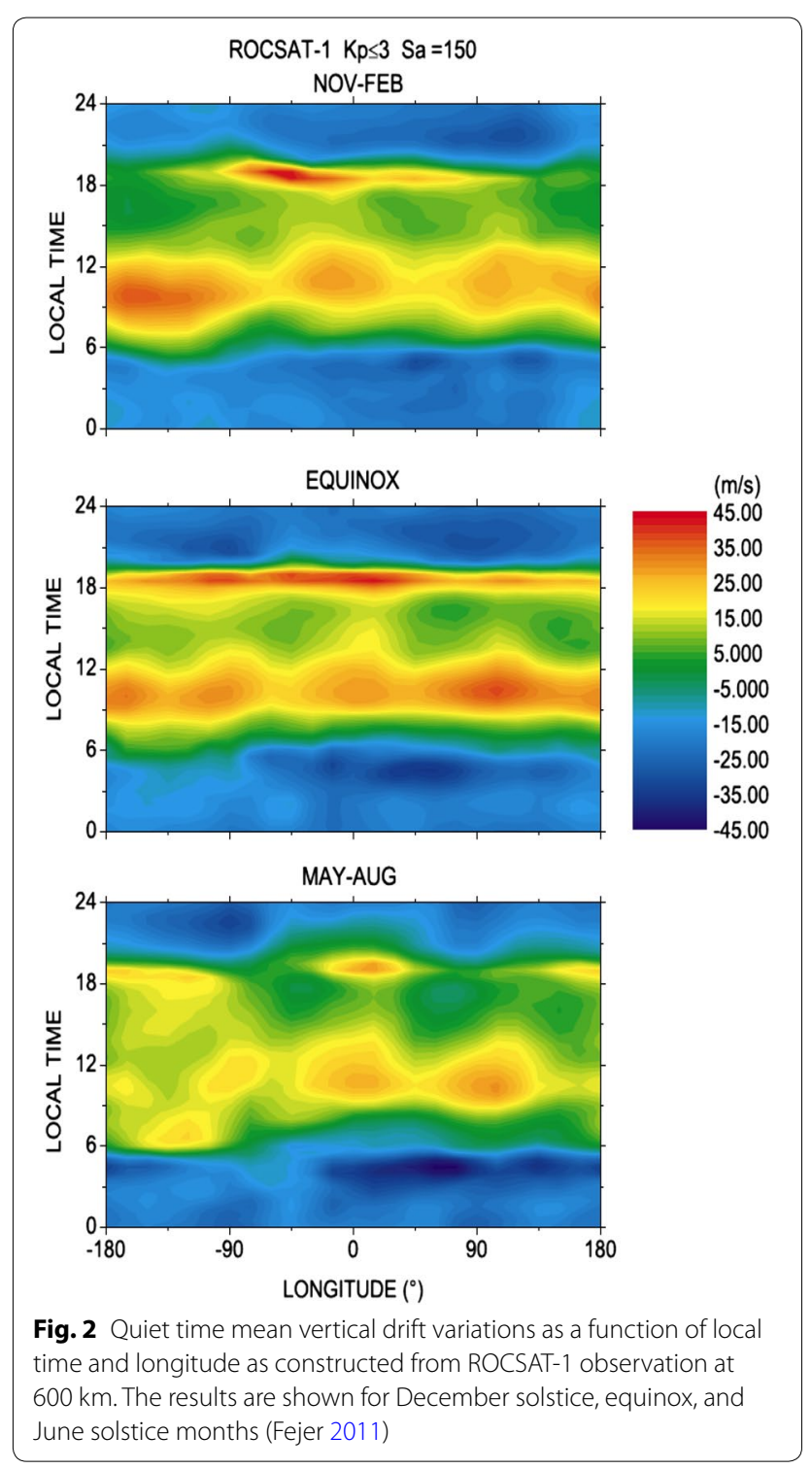


The PRE develops from $F$ layer dynamo driven by the thermospheric zonal wind (eastward in the evening) and under the sunset longitudinal gradient in the $E$ layer conductivity (Rishbeth 1971; Heelis et al. 1974). The sunset terminator alignment with the magnetic meridian that varies with the longitude dependent magnetic declination angle therefore determines the seasonal/longitudinal variation in the PRE amplitude (Abdu et al. 1981a; Batista et al. 1986). For example, the large enhancement in the PRE vertical drift near $45^{\circ} \mathrm{W}$ longitude during December solstice (in Fig. 2) is the result of the large westward magnetic declination $\left(-21^{\circ}\right)$ that characterize this longitude.

The PRE vertical drift is responsible also for the structuring of the night-time ionosphere into plasma irregularities in wide spectrum of scale sizes that can cause severe scintillation (and loss of lock) of satellite signals. The composite of these irregularities widely known as the equatorial spread $F$ (ESF) was first discovered by Booker and Wells 1938 in the form of range spreading echo traces in ionograms. The PRE vertical drift causes the post-sunset rise of the $F$ layer to higher altitudes when the bottom-side gradient region of the rising layer may become unstable to density perturbations whereby the plasma instability grows through Rayleigh-Taylor mechanism leading to the formation of ESF/plasma bubble irregularities (of $10 \mathrm{~s}$ to $100 \mathrm{~s}$ of $\mathrm{kms}$ of scale sizes) that cascade into wide spectrum of smaller scale structures (Haerendel 1973). Figure 3a shows the field aligned structures of plasma bubbles/depletions as their symmetric foot prints at north and south conjugate $F$ layer bottom sides, as captured by ground-based all-sky imagers operated in Brazil (Abdu et al 2012). While the largescale structures are symmetric at the conjugate regions the smaller structures (of decameter sizes) as observed by Digisonde do not map along the entire field lines as can be noted from the corresponding asymmetric spread $F$ traces in ionograms shown Fig. $3 \mathrm{~b}$. These irregularities embedded in the large density background plasma of the EIA as pictured in the TIMED/GUVI map in Fig. 3c can cause strong scintillation, and loss of lock, of the satellite communication and navigation signals.

The quiet time picture described above can undergo drastic modification due to perturbation electric fields also indicated in the schematic diagram of Fig. 1. The perturbation electric fields originate from (1) ionospheric dynamo modified by perturbation winds due to upward propagating waves in the form of gravity waves, planetary waves, and non-migrating tides (green box), and (2) prompt penetration electric field (PPEF) and disturbance dynamo electric field (DDEF) during magnetospheric disturbances (blue box). These disturbances in the electric fields and winds are the drivers of the ionospheric weather variations at low latitudes. Investigations are pursued to understand the nature of the low latitude ionospheric weather and its variability from the perspective of its causes and consequences: The causes of the variabilities are investigated to understand better the coupling processes and the underlying electrodynamics driving them, which is the focus in this paper. The consequences of ionospheric variabilities are understood in terms of their impacts on space-based systems for telecommunication and navigation applications, the details of which will not be discussed here.

\section{The variabilities defining ionospheric weather}

The ionospheric weather may be defined as the shortterm variability in the ionosphere, at time scales of tens of minutes to several days, as observed in its key parameters: equatorial electric fields, plasma drifts and currents, layer peak densities, total electron content (TEC), and density structuring (plasma irregularities). Large variabilities in these parameters can arise due to the response of the ionosphere to the modifications in the electric fields and winds in which ion-neutral coupling and electrodynamic perturbations play key roles. Different types of disturbance conditions and the sources of forcing were mentioned above. Specific examples of the low latitude ionospheric responses under those different sources of forcing will be discussed bellow.

\section{Upward propagating waves from lower atmosphere sources \\ Planetary wave effects during sudden stratospheric warming (SSW) and non-SSW periods}

Extensive observational campaigns in recent years have provided evidence of strong coupling between high and low latitudes during northern hemisphere (arctic) Sudden Stratospheric Warming events. The SSW is caused by rapid growth of quasi-stationary planetary waves, which interact with stratospheric mean circulation, producing large changes in the wind, temperature, and general circulation. Associated with the SSW large perturbations are observed in the equatorial lower and upper atmosphere. Of particular interest are the strong perturbations in the equatorial electrojet current (EEJ) intensity, $F$ region vertical plasma drift/zonal electric field, total electron content of the ionosphere (TEC), and scintillation of GPS signals. An example of the equatorial vertical drift response to the SSW of December 2007January 2008, as measured by the Jicamarca radar, is presented in Fig. 4 (Chau et al. 2009), which shows that the daytime and night-time mean $E \times B$ vertical drifts are highly correlated with the stratospheric temperature and wind deviations (from their 30 year mean values) during the SSW interval of 20-30 January. The daytime vertical drift variations during a set of SSW days as compared 

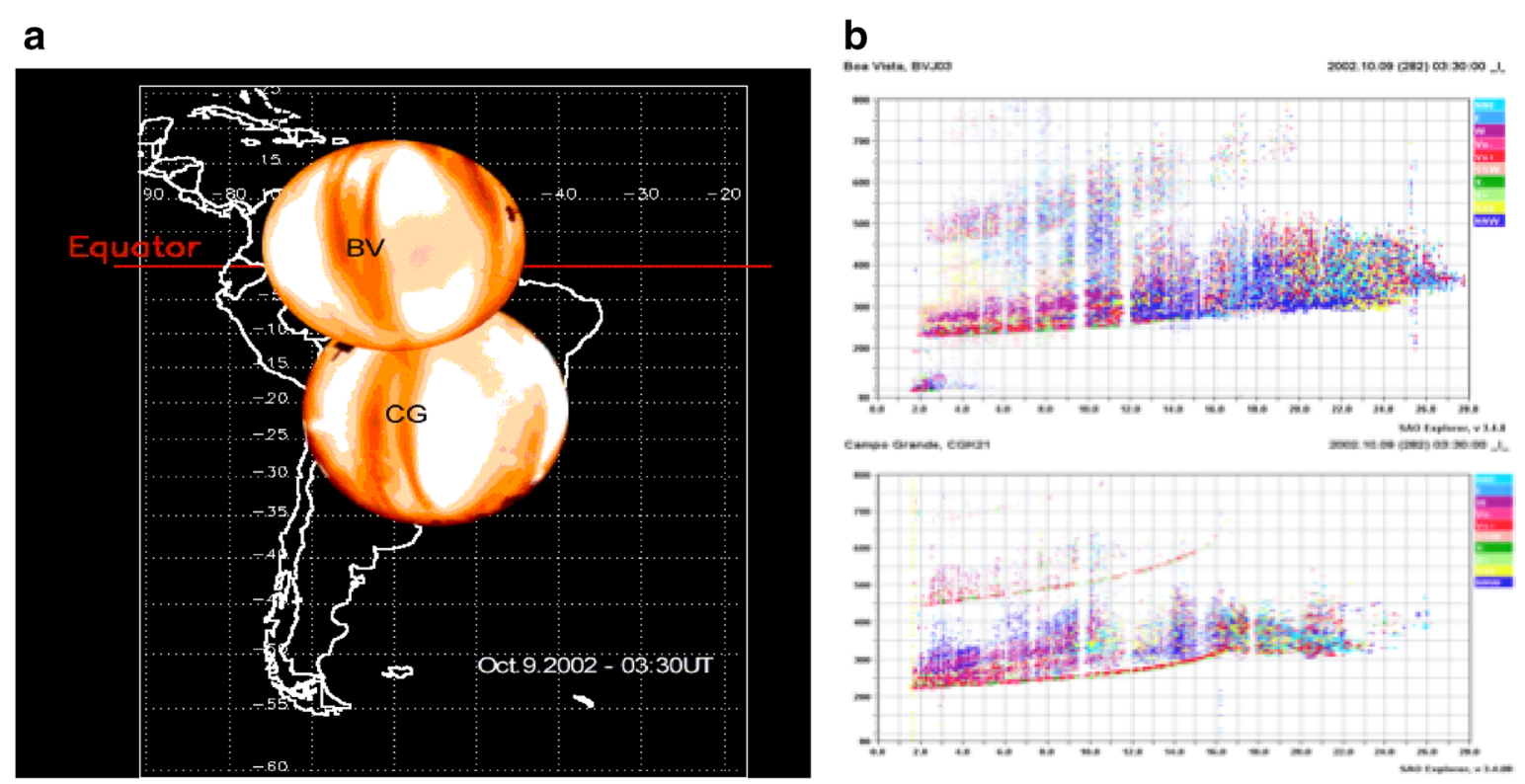

c TIMED/GUVI OI 135.6-nm disk scan DOY 081-082, 2002

UT 11:15 09:38 08:00 06:23 04:46 03:09 01:31 23:54 22:17 20:40 19:02 17:25 15:48 14:11 12:33

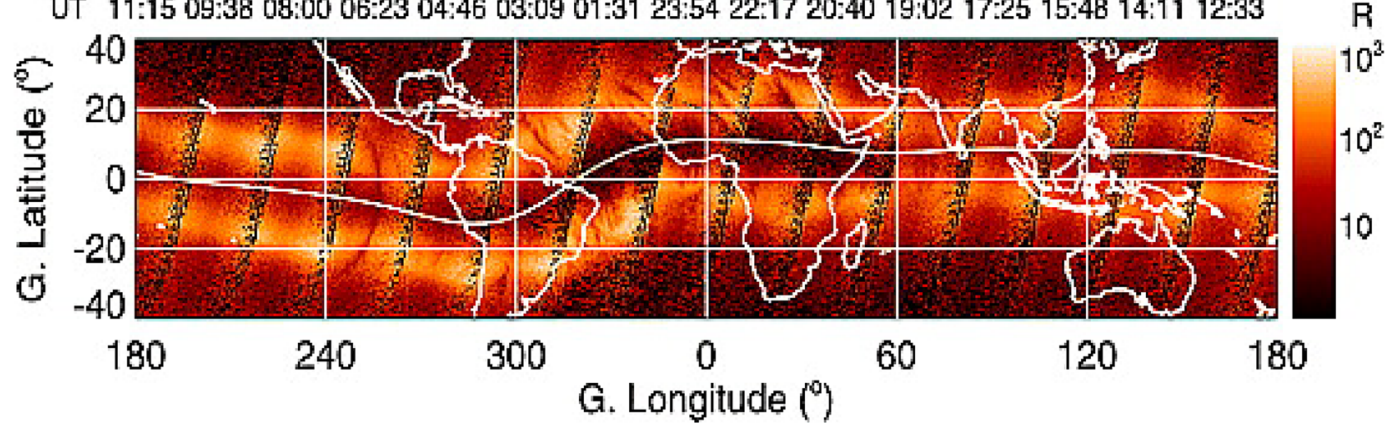

Fig. 3 a All-sky images of Ol 630-nm airglow emission taken at magnetic conjugate points, Boa Vista (BV), and Campo Grande (CG) in Brazil. The images show magnetic North-South aligned airglow depletion patches, symmetric in conjugate images, that are the footprint (in the airglow emission layer) of the flux tube aligned plasma depletions (Abdu et al. 2012); b The corresponding Digisonde ionograms; cTIMED/GUVI 135.6 nm images extending in the entire longitude span showing the global distribution of the ElA brightness and the patches of brightness depletions indicating plasma bubbles symmetric on either side of the dip equator (Kil et al. 2006)

to the corresponding variations on a set of control days presented in Fig. 5 clearly reveal the dominance of semidiurnal oscillations of enhanced amplitudes as the SSW signature on the vertical drift variations over Jicamarca. Such enhancement of the semidiurnal oscillation with intensity peaking at pre noon hours, as observed during a typical day (27 January) of the January 2009 SSW is presented in panel (c) of Fig. 5. Pre noon enhancement of the EIA as a result of the enhanced vertical drift is also shown in the panel (c) of Fig. 5 (Goncharenko et al. 2010). Such EIA enhancement can pose serious problems (like propagation delay) for GNSS-based application systems. On the other hand, equatorial scintillation of GPS signals has been found to undergo weakening during SSW episodes as reported recently by de Paula et al. 2015. These results point to the potential impact of the SSW activity on the equatorial ionospheric weather, and consequently on satellite system applications.

Planetary wave oscillations in the equatorial ionosphere are more often observed during non-SSW periods, as have been well established from numerous investigations in recent years (see for example, Forbes and Leveroni 1992; Chen 1992; Pancheva et al. 2003; Takahashi et al. 2009; Abdu et al. 2006, 2015a). In their upward propagation, (waves of longer vertical wavelengths attaining higher altitude) these waves nonlinearly interact with 


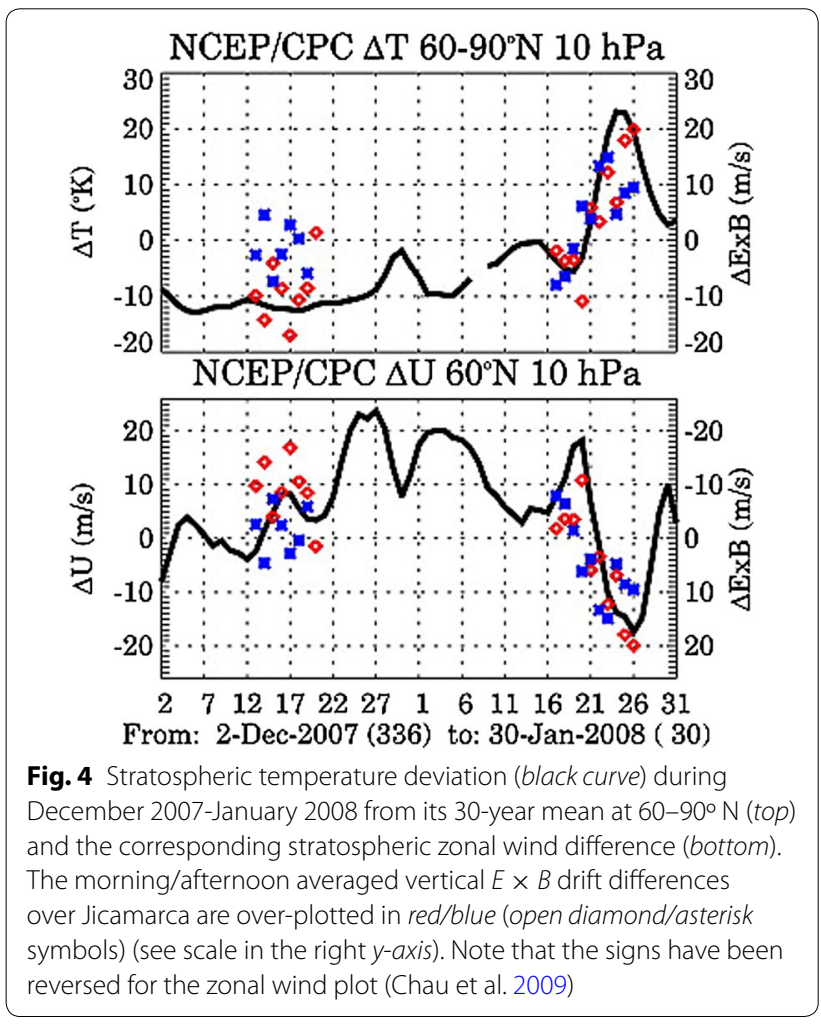

tidal modes whereby electric fields are generated in the dynamo region with consequent modulation of the electrodynamical coupling processes. Oscillations in varying degrees have been observed due to $2,3-5,10$, and 16-days periods in the key ionospheric parameters: the EEJ intensity, post-sunset/night-time $F$ layer heights, evening prereversal enhancement in the $F$ region vertical drift/zonal electric field (PRE), equatorial bubble/ spread $F$ irregularities, etc. Of particular interest for the equatorial region are the Kelvin waves, that is, equatorially trapped eastward propagating planetary waves. Three categories of these waves are identified as slow, fast, and ultra fast Kelvin waves from their distinct periodicities, vertical wavelengths, and propagation characteristics. The fast and ultra fast Kelvin waves (FK and UFK waves), due to their relatively longer vertical wave lengths are capable of propagating to altitudes near $80 \mathrm{~km}$ and higher above probably attaining the dynamo region, shorter period waves dominating with increasing heights (Chen and Miyahara 2012). Through modulation of the tidal oscillations they play key roles in the electrodynamics of the vertical coupling thereby modifying the major ionospheric phenomena.

A UFK wave episode in zonal wind, in its upward propagation, as measured at $87.5,90.0$, and $92.5 \mathrm{~km}$ altitude by TIMED-TIDI, as a function of latitude during January 17-31, 2010 is presented in Fig. 6a (Liu et al.

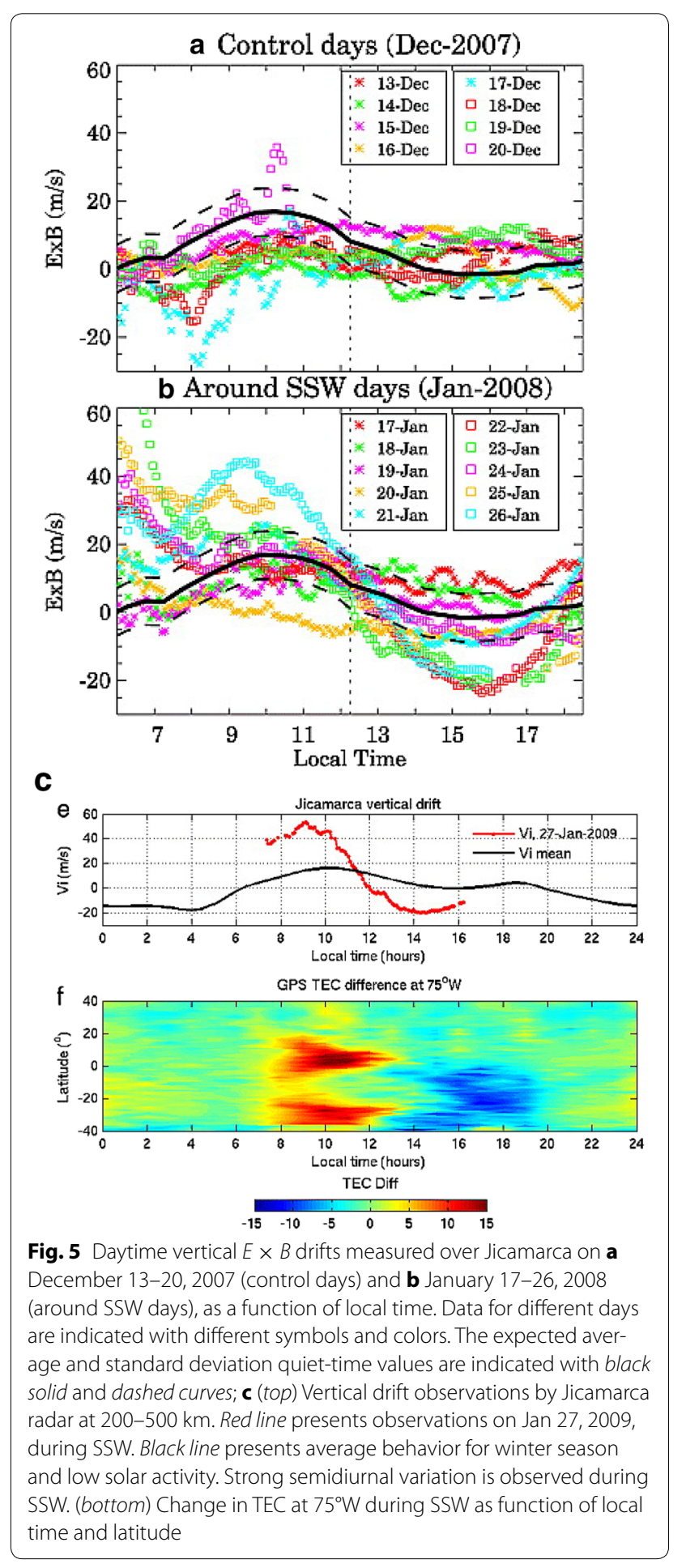

2012). Three-day oscillation, centered at the equator, is clearly defined, with the upward propagation of the wave being evident from the delay in the peak intensity seen with increasing heights. Their interaction with the upward propagating tides resulted in the generation 

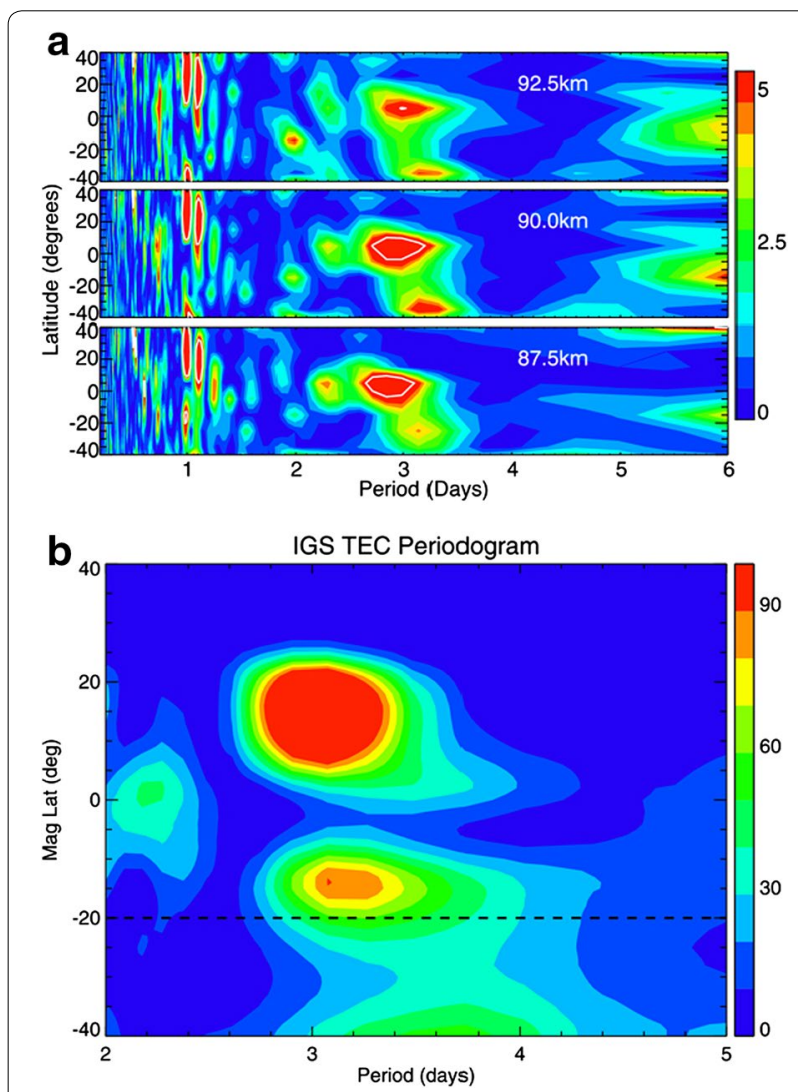

Fig. 6 a Lomb-scargle normalized periodograms of the zonal winds measured by TIMED-TIDI at 87.5, 90.0, and $92.5 \mathrm{~km}$ altitude as a functions of latitude during January 17-31, 2010. The white contour lines mark the $85 \%$ statistical confidence level; b Lomb-scargle periodogram of the IGS TEC values for the selected time interval of January $15-27,2010$ at various magnetic latitudes. The dashed line marks the $20^{\circ} \mathrm{S}$ magnetic latitude (Liu et al. 2012)

of dynamo electric field that was responsible for the 3-day wave in the EIA as seen in the Lomb-scargle periodogram of the IGS TEC presented in Fig. 6b (Liu et al. 2012). UFK wave activity can cause also significant modulation in the equatorial evening prereversal vertical drift (PRE) and consequently in the development of post-sunset spread $F$ (ESF) plasma bubble irregularities. Figure 7 a shows a case of strong modulation of the ESF intensity as well as onset time of the ESF irregularities as observed by a Digisonde over Fortaleza during a UFK wave episode that occurred in October 2005 (Abdu et al. 2015a). It may be noted that the larger PRE amplitude around the day 290 was responsible for the larger intensity and earlier onset time of the post-sunset ESF. The wavelet power spectrum of the PRE in Fig. 7b clearly shows periodicity around 3 days. 3-5 days periodicities were observed also in mesospheric/lower thermospheric zonal wind measured by meteor radars in Brazil and by MF radar in India during the same period

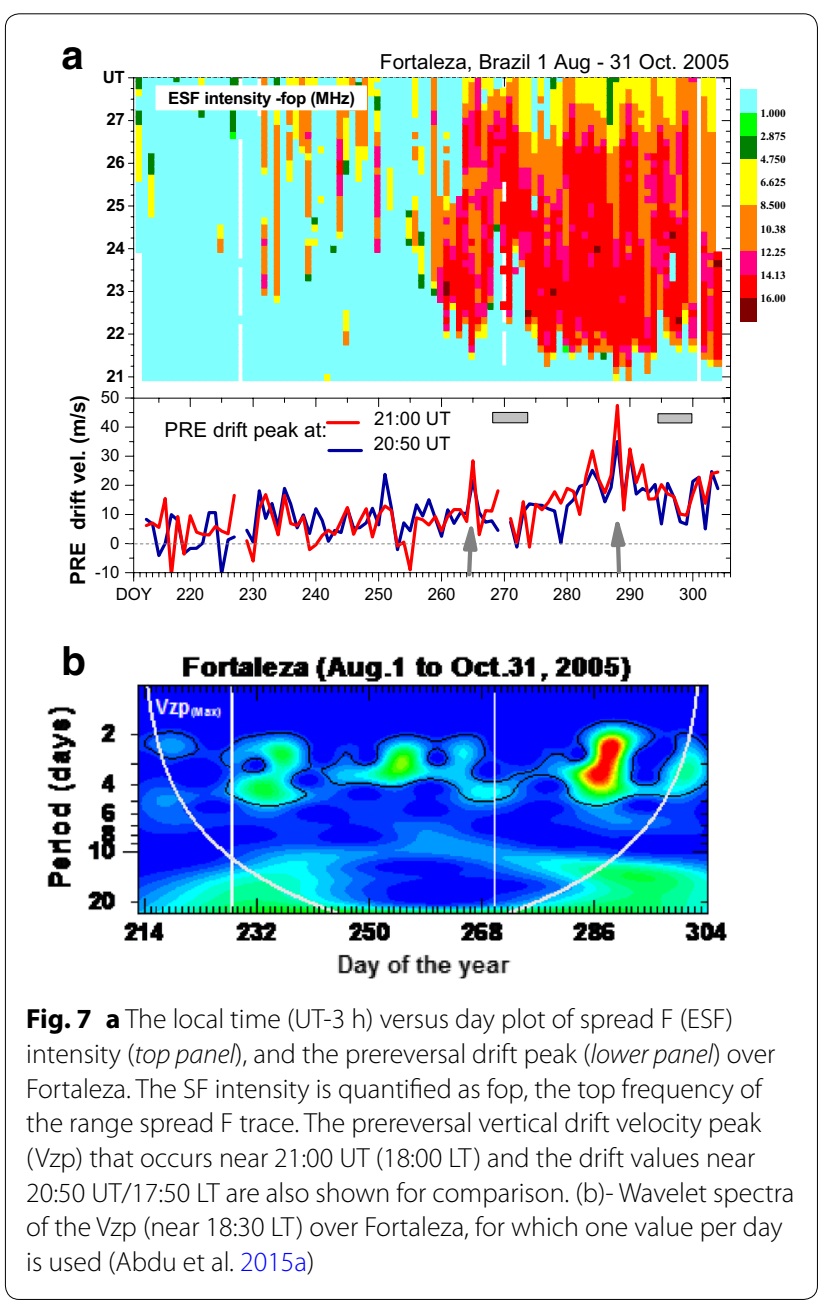

(Abdu et al. 2015a). The upward propagation of these waves was at a rate of 4-5 km per day, thereby attesting to the fact that the upward propagating UFK and FK waves were responsible for the enhanced development of the PRE and ESF over Brazil.

\section{Gravity wave effects on equatorial spread $F$}

Short-term (including day-to-day) variability in the plasma bubble/ESF irregularities of the night-time ionosphere constitute an important component of the equatorial ionospheric weather variability that can impact on space-based application systems. Such variability arises from the variable state of the background ionosphere in the form of precursor conditions. The instability leading to the plasma irregularity formation develops typically through the Rayleigh-Taylor interchange mechanism, operating at the steep bottom-side gradient region of a rapidly rising post-sunset $F$ region. Thus, the enhanced vertical drift of the evening $F$ layer (that is, the post-sunset rise of the layer), due to the PRE in the zonal electric 
field, serves as a primary driver of the ESF. An additional requirement is the presence of a precursor seed perturbation in the ambient electron density with associated polarization electric field required to initiate the instability growth. A number of recent papers have discussed the roles of the precursor conditions for the development of the ESF/plasma bubble irregularities (see, for example, Hysell et al. 2005; Abdu et al. 2009; Taori et al. 2010; Li et al. 2012; Patra et al. 2013). The source of such seed perturbation is now widely recognized to be upward propagating gravity waves originating from tropospheric convective activity as past studies have suggested (for example, Röttger 1973). Conditions for the upward propagation to thermospheric heights of such gravity waves have been widely discussed in the literature (e.g., Fritts et al. 2008; Vadas 2007; Kherani and Abdu 2011). On a statistical basis the seasonal and longitudinal patterns of the ESF occurrence have been attributed in part to gravity wave generation sources associated to the inter-tropical convergence zone (McClure et al. 1998; Tsunoda 2010). Case studies have further supported the role of gravity waves as necessary precursor for the development of the R-T instability leading to ESF irregularities. The precursor gravity wave manifestations can vary depending upon the diagnostic techniques used. Largescale wave structure (LSWS) in the form of upwelling in bottom-side plasma density prior to plume development was observed by incoherent scatter (IS) radar over Kwajelein (Tsunoda and White 1981). Additional $F$ layer traces (satellite traces) were found to be precursor to spread $F$ development in ionograms (Abdu et al. 1981b; Tsunoda 2008; Li et al. 2012). Wave-like ion density structures in the $F$ layer bottom-side, as precursor to plasma bubble development, were observed in situ by atmospheric explorer-E satellite (Singh et al. 1997). Precursor wave structures identified as the LSWS have been observed also in the form of longitudinal wave structure in ionospheric total electron content (TEC) measured on $\mathrm{C} / \mathrm{NOFS}$ satellite passes, as discussed, for example, by (Thampi et al. 2009; Tulasi Ram et al. 2014; Tsunoda et al. 2011) who also found that such LSWS were present in the equatorial ionosphere well before the $E$ layer sunset. Abdu et al. 2009 showed that height oscillations due to LSWS, as observed at $F$ layer bottom-side plasma frequencies by Digisonde, presented upward propagating gravity wave characteristics. These oscillations were present several hours prior to sunset (that is, in the afternoon hours), and their continuation into the post-sunset hours contributed to R-T instability growth resulting in plasma bubble irregularity development. From their estimated zonal scale sizes (of a few to several hundreds of $\mathrm{kms}$ ), these oscillations were identified as signatures of the LSWS (Abdu et al. 2009, 2015b). Takahashi et al. 2010 observed bottom-side sinusoidal intensity depletions in the all-sky images over Cariri and Brasilia, with simultaneous occurrence of bottom-side irregularities as seen by a VHF radar over Sao Luis and bottom-side spread F and height oscillations as seen by a Digisonde over Fortaleza, that were subsequently followed by well-developed plasma bubbles. An example of a composite of such height oscillations observed by a Digisonde operated over Cachinmbo $\left(9.47^{\circ} \mathrm{S}, 54.83^{\circ} \mathrm{W}\right.$; dip: $\left.4.25^{\circ}\right)$ during a 66-day (COPEX) campaign period is presented in Fig. 8 wherein we note height oscillations of significant amplitude during the daytime, getting amplified toward evening hours and further increasing in amplitude as a result of the post-sunset spread $F /$ bubble irregularities that they initiated, as indicated by the gray segment of each curve (with some exceptions that is determined by the PRE vertical drift amplitude, not shown here). It was shown by Abdu et al. 2015b that these height oscillations were driven by polarization electric field induced by upward propagating gravity waves, which therefore represented the precursor seed required for ESF instability growth.

An intriguing aspect of the results in Fig. 8 is that there is a group of days when the gravity wave-induced oscillations are nearly in-phase on all those days, and with larger amplitudes (shown in the upper panel) than on the other group of days when the phases are random (middle panel). Correspondingly, the mean PRE vertical drift amplitudes representing the two groups of days (bottom panel) is significantly larger for the days of larger oscillation amplitude ("coherent" oscillations) than it is for

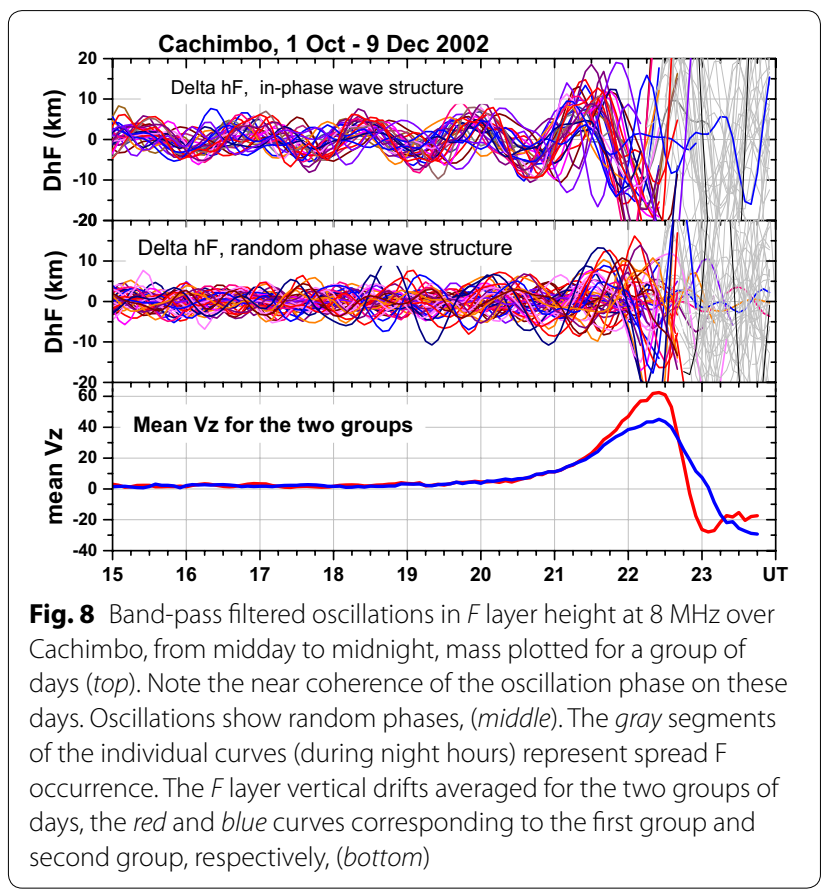


the smaller amplitude (random) oscillations. Based on the well-known role of the $E$ layer tidal winds in shaping the longitudinal/local time gradient in the $E$ layer conductivity at sunset (Abdu et al. 2003), the above results suggested possible tidal modes-gravity wave coupling process impacting on the PRE-ESF relationship (for further details, see Abdu et al. 2015b). This appears to be an important connecting link in determining the precursor conditions for the plasma bubble/ESF irregularity development.

\section{Forcing due to solar and magnetospheric disturbances}

Following a CME-magnetosphere interaction under $\mathrm{Bz}$ south condition, the development of a substorm/storm is marked by $\mathrm{AE}$ and Dst intensifications, when motional electric field, that is interplanetary electric field, IEF, $\left(\mathrm{Bz} \times \mathrm{U}_{\mathrm{sw}}\right)$ maps to high latitudes as dawn-dusk electric field that propagates to low latitudes as prompt penetration/under-shielding electric field having eastward (westward) polarity on the dayside (night-side). With the $\mathrm{Bz}$ turning north, and AE recovery, an over-shielding electric field penetrates to equatorial latitudes that has opposite polarity to the under-shielding/convection electric field (e.g., Kikuchi et al. 2000), the polarities being opposite on the day and night sides. The penetration efficiency of the PPEF can vary so that the ionospheric electric field can be as much as $5-10 \%$ of the IEF (see, for example, Kelley and Retterer 2008; Huang et al. 2010). The intensity and polarity of the penetration electric fields will depend also on large-scale conductivity gradients of the ionosphere so that the daytime eastward electric field extends into postsunset hours peaking near the time of the PRE, prior to its westward reversal by $\sim 21 \mathrm{LT}$, and the night-side westward electric field peaking in the pre-sunrise hours prior to its eastward reversal by 05-07 LT (Richmond et al. 2003; Fejer et al. 2008). The disturbance dynamo electric field (DDEF) arising from the auroral heating that sets off equator-ward thermospheric disturbance winds occurs with a time delay of several hours (from the storm development) (Richmond et al. 2003), and it has the polarity local time dependence similar to that of the over-shielding electric field. These disturbance electric fields are important sources of large variability in the low latitude ionosphere, which will be briefly discussed below.

\section{Variability due to penetration electric fields}

Drastic modifications of the EIA and ESF/plasma bubble irregularity developments can result from disturbance electric fields. The AE index is generally a good indicator of the strength and polarity of these electric fields (Fejer and Scherliess 1995; Abdu 2012). An AE activity with amplitude even as low as $\sim 100 \mathrm{nT}$ (in an otherwise quiet condition) has been found to cause penetration electric fields at equatorial region in the form of EEJ modulation of moderate degree, $(10-20 \mathrm{nT})$, and irregularity development in the EEJ (Abdu 2012). Intense and super storms characterized by large changes in the $\mathrm{AE}$ activity (and Dst decreases) are known to produce large increases on the dayside and evening sector TEC, with the EIA expanding to higher latitude (Abdu 1997; Tsurutani et al. 2004; Mannucci et al. 2005; Lin et al. 2005; Balan et al. 2009). Such redistribution of enhanced low latitude plasma associated with storm time super fountain due to penetration electric field has been invoked to explain the storm-enhanced density (SED) plume phenomenon observed at mid-latitudes in the American longitudes (Foster et al. 2005) as well as in Asia longitude (Maruyama 2006), but with larger amplitude in the American longitude sector that has been attributed to the influence of the South Atlantic Magnetic Anomaly (SAMA) (Foster et al. 2005) where Abdu et al. 2008 observed abnormally large storm time penetration electric field. Such large zonal electric fields are attributed to polarization effect induced by the primary penetration electric field under the presence of large-scale ionospheric conductivity gradients arising from storm time energetic particle precipitation. Thus, large degree of longitude dependent variability in the low latitude ionospheric responses to storm time penetration electric fields has been observed. Such variability has potential impacts on the roles of the EIA and ESF on application systems.

The layer formation processes can be severely modified by height-dependent effects in the response of the low latitude ionosphere to penetration electric field. For example, a rapid increase in the prompt penetration zonal electric field during daytime and evening hours can cause rapid uplift of the $F$ layer. Under continuing photo ionization at lower heights contributing to new $F 2$ layer formation, the previously uplifted (old) $F 2$ layer presents characteristics of an F3 layer (Balan et al. 2011). The formation of such $F 3$ layers can be used as an indicator of the prompt penetration (under-shielding) electric field characterizing the development phase of a storm. At $E$ layer heights, where Hall conduction dominates, a PP zonal electric field can induce Hall vertical electric field that, depending upon the polarity of the primary PPEF (eastward or westward), has been found to cause sporadic $E$ layer formation, or disruption of an $E s$ layer in progress, (Abdu et al. 2013).

Among the variabilities, impacting most on spacebased communication and navigation systems is the variability of the plasma bubble/ESF irregularities due to disturbance electric fields. Depending upon the polarity, such electric fields can cause anomalous development of plasma bubble irregularities, suppress their normal development, or disrupt their development in progress, simply 
by the vertical drift/ $F$ layer height changes brought about by the electric fields.

ESF/Bubble development or disruption due to undershielding electric field. The prompt penetration/undershielding electric field (PPEF) of eastward polarity has largest amplitude in the evening sector (Fejer et al. 2008), and its occurrence almost in-phase with the quiet time PRE can cause post-sunset plasma bubble development during a season of negligible or small PRE value, as June months in Brazil (Abdu et al. 2003). A case of post-sunset bubble development due to an under-shielding electric field, in a bubble non-occurrence season in the Asian longitude sector, during the 10 November 2004 super storm, was presented by Li et al. (2009). The bubble development is faster with increase in the vertical drift that directly contributes to the instability linear growth rate and raises the layer bottom-side to reduced collision frequency domain where the gravity term further enhances the instability growth. Thus the intensity of an ESF event will be greatly enhanced for larger amplitudes of the PPEF, especially, when it occurs overlying on the normal PRE vertical drift. However, there is an upper limit of the vertical drift beyond which bubble development cannot occur, because of the possibly rapid enough change in the ambient conditions that could, with the increasing vertical drift, begin to adversely affect the instability growth rate. For example, Abdu et al. (2008) found that bubble did not develop when the PPEF-induced vertical drift in the postsunset hours attained $\sim 900 \mathrm{~m} / \mathrm{s}$ over Brazil during the super storm of 30th October 2003. The abnormally large vertical drift, as explained by Abdu et al 2008, was caused by polarization electric field arising from large enhancement in the ionospheric conductivity gradients due to energetic particle precipitation in the SAMA region. It is not clear what is the upper threshold limit of the vertical drift for such non-development of bubble irregularities.

The PPEF has westward polarity after $\sim 22 \mathrm{LT}$, and a substorm/storm development at these times can result in plasma downdraft and large depression in the $F$ layer heights. Consequently, the bubble irregularities, in their development, or in developed phase, will be brought down to the height domain of higher collision frequency and recombination rates. As a result, an event in progress will be disrupted as was shown, for example, by Abdu et al. (2013) during the 29 October 2003 super storm sequence.

ESF/Bubble development or suppression due to overshielding, and disturbance dynamo electric fields. An over-shielding electric field associated with a substorm/ storm recovery with the Bz turning north has westward polarity in the evening post-sunset sector, that turns eastward after about 22 LT (Fejer et al. 2008). The largest amplitude of the eastward electric field occurs in the post-midnight hours. The DDEF has also similar polarity local time dependence but it is delayed, generally, by a few hours with respect to the storm onset and the overshielding electric field. However, depending upon the storm duration, the two electric fields may exist simultaneously. An over-shielding electric field that occurs at the time of the evening PRE vertical drift can cause large decrease or even reversal to downward of the vertical drift resulting in the suppression of the post-sunset ESF/ bubble irregularity development during a season of their normal development (see, for example, Abdu 2012). On the other hand, an over-shielding electric field that occurs in the post-midnight hours can cause large increase in plasma vertical drift (Kelley et al. 1979) and the resulting rapid $F$ layer uplift could lead to instability growth by R-T mechanism resulting in ESF/Plasma bubble development (Fejer et al. 1999; Abdu 2012, 1999). An $F$ layer uplift due to disturbance dynamo electric field, which is eastward after 22 LT can lead to development of ESF irregularities, as shown by Abdu (2012). While the isolation of the cause-effect sequence due to the two electric fields is possible for relatively shorter duration/isolated storm events, such a task is not easily accomplished in the cases of log duration event sequences (see also, Scherliess and Fejer 1997).

Variability in bubble zonal drift. An important component of the short-term variability of bubble irregularities over any location concerns the zonal drift of the irregularities, which is eastward under quiet conditions, as is the background plasma drift driven by the dynamo action of the night-time eastward thermospheric wind. However, such drift can be modified drastically, even to reverse westward due to (1) storm time thermospheric zonal wind arising from auroral heating when equatorward disturbance winds acquire westward velocity at low and equatorial latitudes (see for example, Sutton et al. 2005); (2) Hall electric field induced by the PPEF under enhanced night-time $E$ layer conductivity and/ or by reduced $F$ region density (Abdu et al. 1998, 2003). The aspect (2), which is relatively less well-known so far is briefly discussed further below.

The $F$ region zonal plasma drift, $V_{y}$, is related to the field line-integrated Hall-to-Pedersen conductivity ratio, $\sum_{H} / \sum_{P}$, according to the simple relationship:

$$
V_{y}=U_{y}^{P}-\sum_{H} / \sum_{P}\left(V_{z}-U_{Z}^{H}\right),
$$

(See Eccles, 1998), where $U_{y}^{P}$ is the field line-integrated and Pedersen conductivity-weighted zonal wind velocity and $U_{Z}^{H}$ is the Hall conductivity-weighted field line-integrated meridional neutral wind velocity perpendicular to magnetic field. An under-shielding PPEF of eastward polarity that causes a perturbation in upward vertical 
drift $\left(V_{z}\right)$ can produce a westward perturbation in the zonal plasma/bubble drift. An example of zonal drift reversal to westward, under a PPEF of eastward polarity that occurred during the 08-09 November 2004 storm is presented in Fig. 9 (adopted from Santos et al. 2016). The black curves in the panels (c) and (d) are the vertical and zonal drift velocities, respectively, of the ESF/ plasma bubble irregularities, (as measured by a Digisonde at Fortaleza) in which we may note some degree of anti-correlation. The continuous AE activity, especially its steady increases (such as that occurred during 2330-0200 UT) appears to be responsible for a PPEF of eastward polarity starting near 23 UT that caused the $V_{z}$ to increase upward, at the same time causing eastward drift to decrease and to reverse westward by 2140 LT (0040 UT). (Under quiet conditions the bubble zonal drift should continue eastward till pre-sunrise hours). Model calculation of the zonal drift based on Eq. 1, using the $E$ and $F$ region model winds and the conductivity ratio of panel b showed that excellent agreement with the observed drift can be achieved only if an extra ionization by energetic particle precipitation, and thereby enhanced conductivity ratio (red curve in panel b), is included in the model. (See Santos et al. 2016 for more details). It should be pointed out that the presence of enhanced night $E$ layer ionization required for raising the conductivity ratio has been verified from occurrence of anomalous sporadic $E$ layers, as has been observed in the SAMA region (Abdu et al. 2013). Cases of slower eastward velocity of the bubbles with their subsequent westward reversal have been reported for other longitude sectors. Basu et al. (2010) observed westward reversal of scintillation irregularity drift over Peru well into the Dst development and recovery phase of 7-8 Nov 2004 storm. The AE activity that accompanied the event suggested possible roles, in varying degrees, of both the Hall electric field as well as the disturbance zonal wind induced contributions to the observed drift pattern. During the

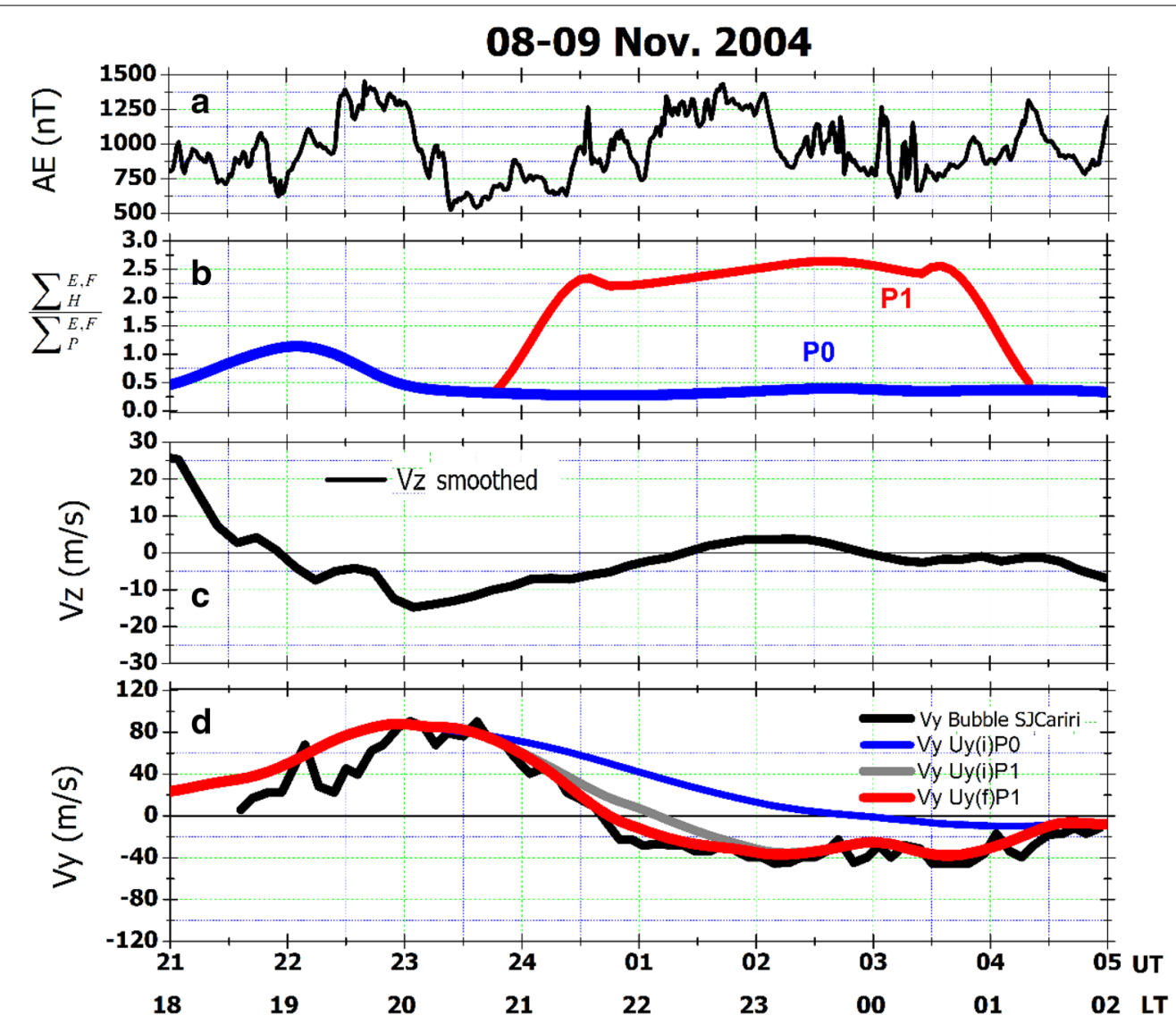

Fig. 9 From the top to the bottom are presented: the AE index on 8-9 November 2004 (panel a), the ratio $\sum_{H} / \sum_{p}$ considering (P1)/not considering (PO) the effects of energetic particle precipitation (panel b), and the observed vertical drift (panel c). In panel " $d$ " are shown the observed (black line) and calculated zonal drift considering the initial winds and non inclusion of the precipitation (blue curve), inclusion of precipitation and enhanced ratio of $\sum_{H} / \sum_{p}$ (gray curve), and inclusion of the modified $E$ and $F$ layer winds, precipitation and the enhanced $\sum_{H} / \sum_{p}$ (red curve). The observed vertical and zonal drifts are from the Digisonde at Fortaleza 
same storm sequence on 10 November $2004 \mathrm{Li}$ et al. (2009) observed over Wuhan westward drift of GPS TEC irregularities during the recovery phase of a long duration storm, which pointed to the dominant role of disturbance zonal wind in driving the observed zonal drift. The isolation of the sources driving the drift is an important requirement for a better evaluation of the variability in the bubble zonal drift and hence in the variability in the irregularity occurrence over any given location.

\section{Discussion and conclusions}

The elements controlling the ionospheric weather can be represented by: electric fields, currents, plasma drifts, instabilities, and plasma structuring. They suffer variability due to (1) upward propagating waves from their sources in the lower atmosphere, which include: planetary waves (with or without SSW), Kelvin waves, their interactions with tidal modes resulting in electric field generation by $E$ - and $F$ - layer dynamo, and gravity waves; (2) solar and magnetospheric disturbances that cause penetration electric fields, disturbance winds, and disturbance dynamo electric field that prevail over low latitudes. A detailed understanding of the variabilities in these component parameters at different time and space scales in terms of the phenomenology and cause-effect sequence, and adequate data bank, are fundamental requirements for developing predictive capabilities. As a result of the extensive research in the field during the last several decades, a good degree of success has been achieved on prediction models as far as the climatology of the different phenomena is concerned. However, the situation is less than satisfactory regarding the predictive capability for short-term and day-to-day variabilities, which is to be expected because the nature of the corresponding driving sources originating from above and below (as mentioned earlier) are not easily tractable. Disturbance electric fields originating from the upward propagating waves on the one hand and those originating from solar wind-magnetosphere-ionosphere interactions on the other are the specific sources that cause the shortterm and day-to-day variabilities. How well they can be predicted will determine to a large degree the success for predicting the ionospheric weather. The predictive models should address the ionospheric structuring in wide ranges of scales sizes: the small-medium scales that define plasma bubble irregularities that cause radio wave scintillations and the large scales defining the equatorial ionization anomaly that impose propagation delay on satellite communication and navigation signals. There are also issues such as (a) the simple occurrence of an event (say, plasma bubble irregularity or a scintillation event) and (b) the intensity and space-time evolution of that event. Depending upon the specific problem and limitation of the scope (such as advance in time) some degree of success has been achieved with respect to both the issues (a) and (b). Kelley and Retterer (2008) used solar wind data obtained from upstream of the Earth and physics-based assimilative model to predict a bubble irregularity event during a severe magnetic storm that occurred on 9-10 November 2004. Their model results appeared to agree reasonably with one test case of development and evolution of a bubble event over Jicamarca as observed by the IS Radar. Carter et al. (2014) have used, with partial success, the Thermosphere Ionosphere Electrodynamics General Circulation Model (TEIGCM) to show that the variability in magnetic activity (reckoned in terms of day-to-day variation in the Kp index) could control in a predictable way the variability in plasma bubble occurrence (represented by the GPS signal scintillation) during the scintillation season over Asian longitude sector. There has been attempt to predict longitude-local time distribution of scintillation based on the perceived role of gravity waves in initiating the bubble growth. Assuming day-to-night continuity and integrity of the $F$ layer electron density perturbation produced by gravity waves and the relationship between the total duration of spread- $F$ and $F$ layer base height, Sridharan et al. (2014) developed a model for predicting the local time-longitude distribution of the scintillation from the knowledge of the F layer parameters measured at earlier local times.

Achieving the desired level of predictive capability on low latitude ionospheric weather disturbances remains to be a long-term objective by the scientific community. Some guidelines can be proposed as examples of those helpful for the continuing progress: (1) Detection and characterization of upward propagating Planetary waves/Kelvin waves at stratospheric and mesospheric heights can be used to predict with a few days in advance their modifications of the EIA, the PRE and the associated ESF/bubble developments, from the knowledge of the upward propagation velocities and other-related characteristics of these waves (Abdu et al. 2015a). On a similar principle, the identification of tropospheric convective activity in the equatorial region (associated with the inter-tropical convergence zone, ITCZ) and characterization of the upward propagating gravity waves therefrom will be a step toward predicting ESF/plasma bubble occurrence a few hours ahead of its post-sunset development; (2) Measurement of solar wind and interplanetary magnetic field from satellites (such as the ACE) stationed the at L1 libration point (at 1.5 million $\mathrm{km}$ away, and $1 \mathrm{~h}$ upstream of the Earth) can be used to predict, with the help of assimilative modeling, the development of equatorial bubble/ESF irregularities and the EIA around $1.5 \mathrm{~h}$ ahead of their occurrences. In summary, we may note:(1) although we now have reasonably 
good predictive capability on the climatology of the low latitude ionosphere, our progress in describing/modeling the short-term variability is still in the beginning stage, (2) the electrodynamics of the coupling processes that control the ionospheric variability is reasonably well understood, as many recent global simulation model results have shown (though not discussed here). However, data base on the ionospheric structuring and key driving parameters, such as perturbation electric fields and winds (under disturbed and quiet conditions) needs further enrichment and improvement (from satellite and ground-based observations) for making continuing progress toward achieving better predictive capability on the ionospheric weather.

\section{Author details \\ ${ }^{1}$ Instituto Tecnológico de Aeronáutico (ITA), DCTA, São Jose dos Campos, Bra- zil. $^{2}$ INPE-National Institute for Space Research, Sao Jose dos Campos, Brazil.}

\section{Acknowledgements}

The author acknowledges the support received from the Coordenação de Aperfeiçoamento de Pessoal de Nível Superior (Capes) for a senior visiting professorship at ITA/DCTA. This work was supported also by the Conselho Nacional de Desenvolvimento Científico e Tecnológico (CNPq) through the process: CNPq no. 300883/2008-0. The author wishes to thank Dr. A.M. Santos for preparing Fig. 9 of this paper.

\section{Competing interests}

The author declares that he has no competing interests.

Received: 26 January 2016 Accepted: 1 March 2016

Published online: 18 March 2016

\section{References}

Abdu MA (1997) Major phenomena of the equatorial ionosphere-thermosphere system under disturbed conditions. J Atmos Sol Terr Phys 59(13):1505-1519

Abdu MA (2012) Equatorial spread F/plasma bubble irregularities under storm time disturbance electric fields. J Atmos Sol Terr Phys 75(76):44-56

Abdu MA, Batista IS, Bittencourt JA (1981a) Some characteristics of spread $\mathrm{F}$ at the magnetic equatorial station Fortaleza. J Geophys Res 86:6836. doi:10.1029/JA086iA08p06836

Abdu MA, Bittencourt JA, Batista IS (1981b) Magnetic declination control of the equatorial $F$ region dynamo electric field development and spread $F$. J Geophys Res 86(11):443-446

Abdu MA, Jayachandran PT, MacDougall JW, Sobral JHA (1998) Equatorial F region zonal plasma irregularity drifts under magnetospheric disturbances. Geophys Res Lett 25:4137-4140. doi:10.1029/L900117

Abdu MA, Batista IS, Takahashi H, MacDougall J, Sobral JH, Medeiros AF, Trivedi NB (2003) Magnetospheric disturbance induced equatorial plasma bubble development and dynamics: a case study in Brazilian sector. J Geophys Res 108(12):1449. doi:10.1029/2002JA009721

Abdu MA, Batista PP, Batista IS, Brum CGM, Carrasco AJ, Reinisch BW (2006) Planetary wave oscillations in mesospheric winds, equatorial evening prereversal electric field and spread F. Geophys Res Lett 33:07107. doi:10. 1029/2005GL024837

Abdu MA et al (2008) Abnormal evening vertical plasma drift and effects on ESF and EIA over Brazil-South Atlantic sector during the 30 October 2003 superstorm. J Geophys Res 113:A07313. doi:10.1029/2007JA012844

Abdu MA, Kherani EA, Batista IS, de Paula ER, Fritts DC, Sobral JHA (2009) Gravity wave initiation of equatorial spread F/plasma bubble irregularities based on observational data from the SpreadFEx campaign. Ann Geophys 27:2607-2622
Abdu MA, Batista IS, Reinisch BW, MacDougall JW, Kherani EA, Sobral JHA (2012) Equatorial range spread $\mathrm{F}$ echoes from coherent backscatter, and irregularity growth processes, from conjugate point digital ionograms. Radio Sci. 47:6003. doi:10.1029/2012RS005002

Abdu MA, Souza JR, Batista IS, Fejer BG, Sobral JHA (2013) Sporadic E layer development and disruption at low latitudes by prompt penetration electric fields during magnetic storms. J Geophys Res Space Phys 118:2639-2647. doi:10.1002/jgra.50271

Abdu MA, Brum CGM, Batista PP, Gurubaran S, Pancheva D, Bageston JV, Batista IS, Takahashi H (2015a) Fast and ultrafast Kelvin wave modulations of the equatorial evening $F$ region vertical drift and spread $F$ development. Earth Planet Space 67:1. doi:10.1186/s40623-014-0143-5

Abdu MA, de Souza JR, Kherani EA, Batista IS, MacDougall JW, Sobral JHA (2015b) Wave structure and polarization electric field development in the bottomside F layer leading to postsunset equatorial spread F. J Geophys Res Space Phys. doi:10.1002/2015JA021235

Balan N, Shiokawa K, Otsuka Y, Watanabe S, Bailey GJ (2009) Super plasma fountain and equatorial ionizationanomaly during penetration electric field. J Geophys Res 114:A03310. doi:10.1029/2008JA013768

Balan N et al (2011) A statistical study of the response of the dayside equatoria F2 layer to the main phase of intense geomagnetic storms as an indicator of penetration electric field. J Geophys Res 116:A03323. doi:10.1029/201 OJA016001

Basu S, Basu S, MacKenzie E, Bridgwood C, Valladares CE, Groves KM, Carrano C (2010) Specification of the occurrence of equatorial ionospheric scintillations during the main phase of large magnetic storms within solar cycle 23. Radio Sci 45:5009. doi:10.1029/2009RS004343

Batista IS, Abdu MA, Bittencourt JA (1986) Equatorial F-region vertical plasma drifts: seasonal and longitudinal asymmetries in the American sector. J Geophys Res 91:12055-12064

Booker HG, Wells HW (1938) Scattering of radio waves in the $F$ region of ionosphere. J Geophys Res 43:249-256. doi:10.1029/TE043i003p00249

Carter BA, Yizengaw E, Retterer JM, Francis M, Terkildsen M, Marshall R, Norman R, Zhang K (2014) An analysis of the quiet time day-to-day variability in the formation of postsunset equatorial plasma bubbles in the Southeast Asian region. J Geophys Res Space Phys 119:3206-3223. doi:10.1002/20 13JA019570

Chau JL, Fejer BG, Goncharenko LP (2009) Quiet variability of equatorial $E \times B$ drifts during a sudden stratospheric warming event. Geophys Res Lett 36(5):1-4. doi:10.1029/2008GL036785

Chen P-R (1992) Two-day oscillations of the equatorial ionization anomaly. J Geophys Res 97(A5):6343-6357

Chen Y-W, Miyahara S (2012) Analysis of fast and ultrafast Kelvin waves simulated by the Kyushu-GCM. Atmos Solar-Terr Phys 80:1-11

de Paula ER, Jonah OF, Moraes AO, Kherani EA, Fejer BG, Abdu MA, Muella MTAH, Batista IS, Dutra SLG, Paes RR (2015) Low-latitude scintillation weakening during sudden stratospheric warming events. J Geophys Res Space Phys 120:2014J. doi:10.1002/A020731

Eccles JV (1998) A simple model of low latitude electric fields. J Geophys Res 103:26699-26708

Fejer BG (2011) Low latitude ionospheric electrodynamics. Space Sci Rev 158:145-166. doi:10.1007/s11214-010-9690-7

Fejer BG, Scherliess L (1995) Time dependent response of equatorial ionospheric electric field to magnetospheric disturbances. Geophys Res Lett 22:851-854

Fejer BG, Scherliess L, de Paula ER (1999) Effects of the vertical plasma drift velocity on the generation and evolution of equatorial spread F. J Geophys Res 104(9):19859-19869

Fejer BG, Jensen JW, Su S-Y (2008) Seasonal and longitudinal dependence of equatorial disturbance vertical plasma drifts. Geophys Res Lett 35(L20106):2008G. doi:10.1029/L035584

Forbes JM, Leveroni S (1992) Quasi16-day oscillations in the ionosphere. Geophys Res Lett 19:981-984

Foster JC, Coster AJ, Erickson PJ, Rideout W, Rich FJ, Immel TJ, Sandel BR (2005) Redistribution of the storm time ionosphere and the formation of a plasmaspheric bulge, in inner magnetosphere inter-actions: New perspectives from imaging AGU. Geophys Monogr Ser 277-289

Fritts DC et al (2008) Gravity wave and tidal influences on equatorial spread F based on observations during the spread $F$ experiment (SpreadFEx). Ann Geophys 26:3235-3252 
Goncharenko LP, Chau JL, Liu H-L (2010G) Coster AJ (2010) Unexpected connections between the stratosphere and ionosphere. Geophys Res Lett 37(10):1-6. doi:10.1029/L043125

Haerendel G (1973) Theory of equatorial spread F. Report: Maxplanck-Institut fur Extraterre. Phys Garching, Germany

Heelis RA, Kendall PC, MoCet RJ, Windle DW, Rishbeth H (1974) Electrical coupling of the $E$ and $F$ regions and its effect on the $F$ region drifts and winds. Planetary Space Sci 22:743-756

Huang C-S, Rich FJ, Burke WJ (2010) Storm time electric fields in the equatorial ionosphere observed near the dusk meridian. J Geophys Res 115:A08313. doi:10.1029/2009JA015150

Hysell DL, Kudeki E, Chau JL (2005) Possible ionospheric preconditioning by shear flow leading to equatorial spread F. Ann Geophys 23:2647-2655

Kelley MC, Retterer J (2008) First successful prediction of a convective equatorial ionospheric storm using solar wind parameters. Space Weather 6:S08003. doi:10.1029/2007SW000381

Kelley MC, Fejer BG, Gonzales CA (1979) An explanation for anomalous equatorial ionospheric electric field associated with a northward turning of the interplanetary magnetic field. Geophys Res Lett 6:301

Kherani EA, Abdu MA (2011) The acoustic gravity wave induced disturbances in the equatorial ionosphere. In: IAGA/IUGG Springer (ed). Aeronomy of the earth's atmosphere and ionosphere, vol 1, 1st edn. Springer, Dordrecht, p 141-162

Kil H, DeMajistre M, Paxton LJ, Zhang Y (2006) F-region Pedersen conductivity deduced using the TIMED/GUVI limb retrievals. Ann Geophys 24:1311-1316

Kikuchi T, Luehr H, Schlegel K, Tachihara H, Shinohara M, Kitamura T-I (2000) Penetration of auroral electric fields to the equator during a substorm. J Geophys Res 105:23251-23261

Li G, Ning B, Zhao B, Liu L, Wan W, Ding F, Xu JS, Liu JY, Yumoto K (2009) Characterizing the 10 November 2004 storm-time middle-latitude plasma bubble event in Southeast Asia using multi-instrument observations. J Geophys Res 114:A07304. doi:10.1029/2009JA014057

Li G, Ning B, Abdu MA, Wan W, Hu L (2012) Precursor signatures and evolution of post-sunset equatorial spread-F observed over Sanya. J Geophys Res 117:A08321. doi:10.1029/2012JA017820

Lin CH, Richmond AD, Liu JY, Yeh HC, Paxton LJ, Lu G, Tsai HF, Su S-Y (2005) Large-scale variations of the low-latitude ionosphere during the october-november 2003 superstorm: observational results. J Geophys Res 110:A0928. doi:10.1029/2004JA010900

Liu G, England SL, Immel TJ, Kumar KK, Ramkumar G, Goncharenko LP (2012) Signatures of the 3-day wave in the low-latitude and midlatitude ionosphere during the January 2010 URSI World Day campaign. J Geophys Res 117:A06305. doi:10.1029/2012JA017588

Mannucci AJ, Tsurutani BT, lijima BA, Komjathy A, Saito A, Gonzalez WD, Guarnieri FL, Kozyra JU, Skoug R (2005) Dayside global ionospheric response to the major interplanetary events of october 29-30, 2003 " $\mathrm{Hal}$ loween Storms". Geophys Res Lett 32:1202. doi:10.1029/2004GL021467

Maruyama T (2006) Extreme enhancement in total electron content after sunset on 8 November 2004 and its connection with storm enhanced density. Geophys Res Lett 33:L20111. doi:10.1029/2006GL027367

McClure JP, Sing S, Bamgboye DK, Johnson FS, Kil H (1998) Occurrence of equatorial $F$ region irregularities: evidence for tropospheric seeding. J Geophys Res 103:29119-29135

Namba S, Maeda K-I (1938) Radio wave propagation. Tokyo, Corona, p 86

Pancheva D, Haldoupis C, Meek CE, Manson AH, Mitchell NJ (2003) Evidence of a role for modulated atmospheric tides in the dependence of sporadic E layers on planetary waves. J Geophys Res 108(A5):1176. doi:10.1029/20 02JA009788

Patra AK, Taori A, Chaitanya PP, Sripathi S (2013) Direct detection of wavelike spatial structure at the bottom of the F region and its role on the formation of equatorial plasma bubble. J Geophys Res Space Phys 118:11961202. doi:10.1002/jgra.50148
Richmond AD, Peymirat C, Roble RG (2003) Long-lasting disturbances in the equatorial ionospheric electric field simulated with a coupled magnetosphere-ionosphere-thermosphere model. J Geophys Res 108(A3):1118. doi:10.1029/2002JA009758

Rishbeth H (1971) Polarization 4elds produced by winds in the equatorial $F$ region. Planet Space Sci 19:357-369

Röttger J (1973) Wavelike structures of large scale equatorial spread F irregularities. J Atmos Sol Terr Phys 35:1195-1996

Santos AM, Abdu MA, de Souza JR, Sobral HA, Batista IS, Denardini CM (2016) Stormtime equatorial plasma bubble zonal drift reversal due 1 to disturbed Hall electric field over the Brazilian region. J Geophys Res (in press)

Scherliess L, Fejer BG (1997) Storm time dependence of equatorial disturbance dynamo zonal electric fields. J Geophys Res 102(A11):24037-24046

Singh S, Johnson FS, Power RA (1997) Gravity wave seeding of equatorial plasma bubbles. J Geophys Res 102(4):7399-7410

Sridharan R, Bagiya MS, Sunda S, Choudhary R, Pant TK, Jose L (2014) First results on forecasting the spatial occurrence pattern of L-band scintillation and its temporal evolution. J Atmos Sol Terr Phys 19:53-62

Sutton EK, Forbes JM, Nerem RS (2005) Global thermospheric neutral density and wind response to the severe 2003 geomagnetic storms from CHAMP accelerometer data. J Geophys Res 110:A09S40. doi:10.1029/20 04JA010985

Takahashi H, Abdu MA, Wrasse CM, Fechine J, Batista IS, Pancheva D, Lima LM, Batista PP, Clemesha BR, Shiokawa K, Gobbi D, Mlynczak MG, Russel JM (2009) Possible influence of ultra-fast Kelvin wave on the equatorial ionosphere evening uplifting. Earth Planet Space 61:455-462

Takahashi H, Abdu MA, Taylor MJ, Pautet P-D, de Paula E, Kherani EA et al (2010) Equatorial ionosphere bottom-type spread F observed by OI 630.0 nm airglow imaging. Geophys Res Lett 37:L03102. doi:10.1029/200 9GL041802

Taori A, Makela JJ, Taylor M (2010) Mesospheric wave signatures and equatorial plasma bubbles: a case study. J Geophys Res 115:A06302. doi:10.1029/2 009JA015088

Thampi SV, Yamamoto M, Tsunoda RT, Otsuka Y, Tsugawa T, Uemoto J, Ishii M (2009) First observations of large-scale wave structure and equatorial spread F using CERTO radio beacon on the C/NOFS satellite. Geophys Res Lett 36:L18111. doi:10.1029/2009GL039887

Tsunoda RT (2008) Satellite traces: an ionogram signature for large-scale wave structure and a precursor for equatorial spread F. Geophys Res Lett 35:L20110. doi:10.1029/2008GL035706

Tsunoda RT (2010) On seeding equatorial spread F during solstices. Geophys Res Lett 37:L05102. doi:10.1029/2010GL042576

Tsunoda RT, White BR (1981) On the generation and growth of equatorial backscatter plumes: 1. wave structure in the bottomside $F$ layer. J Geophys Res 86:3610-3616. doi:10.1029/JA086iA05p03610

Tsunoda RT, Yamamoto M, Tsugawa T, Hoang TL, Tulasi Ram S, Thampi SV, Chau HD, Nagatsuma T (2011) On seeding, large scale wave structure, equatorial spread F, and scintillations over Vietnam. Geophys Res Lett 38:L20102. doi:10.1029/2011GL049173

Tsurutani B et al (2004) Global dayside ionospheric uplift and enhancement associated with interplanetary electric fields. J Geophys Res 109:A08302. doi:10.1029/2003JA010342

Tulasi Ram S, Yamamoto M, Tsunoda RT, Chau HD, Hoang TL, Damtie B, Wassaie M, Yatini CY, Manik T, Tsugawa T (2014) Characteristics of large-scale wave structure observed from African and Southeast Asian longitudinal sectors. J Geophys Res Space Phys 119:2288-2297. doi:10.1002/201 3JA019712

Vadas SL (2007) Horizontal and vertical propagation and dissipation of gravity waves in the thermosphere from lower atmospheric and thermospheric sources. J Geophys Res 112:A06305. doi:10.1029/2006JA011845 